\title{
Prensa escrita mendocina y construcción identitaria sobre los pueblos originarios de Argentina
}

\author{
J. Manuel López, Osvaldo Sironi y Leonardo CASTILLO \\ CONICET - Facultad de Filosofía y Letras, Universidad Nacional de Cuyo - CIRSF-MAF. \\ mlopez@mendoza-conicet.gob.ar osvaldosironi@yahoo.com.ar lcastillo@mendoza-conicet.gob.ar
}

Recibido: 14 de agosto de 2013

Aceptado: 30 de noviembre de 2014

\section{RESUMEN}

En el siguiente trabajo presentamos un estudio multidimensional sobre la conceptualización de los pueblos originarios que han constituido los medios de prensa escrita en Mendoza durante la primera década del siglo XX. Para llevarlo a cabo acudimos al Archivo de Hemeroteca de la Biblioteca General San Martín de la Ciudad de Mendoza, teniendo como referencia al Diario Los Andes, principal periódico de la provincia, creado en 1882 y vigente en la actualidad. El objetivo del estudio es la identificación de las distintas formas de construcción conceptual sobre los pueblos etnográficos del actual territorio argentino que difundió dicho diario, y del modo en que dichos artículos periodísticos jugaron un rol activo en relación con el proceso de construcción de alteridad sociocultural y la legitimación de las políticas etnocidas implementadas por las clases dominantes.

Palabras clave: Pueblos originarios, prensa escrita, primera década del siglo XX, alteridad sociocultural.

\section{News Media of Mendoza and Identity Construction on Ethnic Groups of Argentina}

\begin{abstract}
In this paper we present a multidimensional study of the conceptualization of indigenous peoples by print media in Mendoza during the first decade of the twentieth century. To carry it out, we investigated at the Newspaper Archive of General San Martin Library of the City of Mendoza, taking as a reference the Diario Los Andes, the main newspaper of the province, created in 1882 and currently in force. This study aims to identify the various forms of conceptual construction on the ethnographic peoples in Argentine territory spread by newspaper articles, and how these played an active role in relation to the process of building cultural otherness and the legitimation of the ethnocide policy implemented by ruling classes.
\end{abstract}

Key words: Ethnic groups, news media, alterity, first decade of $20^{\text {th }}$ century, Mendoza.

Sumario: 1. Introducción. 2. Materiales y método 3. «Los hombres se parecen más a su época que a su padre». 4. «Dime de qué hablas y te diré qué eres». 5. «Dime de qué hablas y te diré quién eres». 6. «Dime de qué hablas y te diré quién fuiste». 7 Discusiones finales. 8. Referencias bibliográficas.

$$
\begin{array}{r}
\text { Menos mal que existen } \\
\text { los que no tienen nada que perder } \\
\text { ni siquiera la historia. } \\
\text { Silvio Rodríguez }
\end{array}
$$

\section{Introducción}

Durante mucho tiempo se nos ha inculcado que el Estado Nacional Argentino terminó de imponer su hegemonía sobre los pueblos originarios que habitaron el territorio de la posterior República al finalizar la «Conquista del Desierto», organizada por Roca entre 1879-1885. Entendemos que a pesar del crecimiento y la acumulación de la época, caracterizada por la imposición del modelo agroexportador, seguía habiendo un superávit insuficiente para efectuar la disolución de las formas no capitalistas de la organización social de la producción: 
«La difusión de las regiones de producción capitalista en América Latina no eliminó todas las propiedades corporativas precapitalistas, las propiedades comunales, los cultivadores campesinos y los derechos consuetudinarios de usufructo de las tierras de los latifundios, pero la nueva matriz social y económica de la época dio un significado en gran parte diferente a la posición de todos estos vestigios culturales» (Glade 1991: 30).

Una mirada sobre el acercamiento periodístico a los grupos étnicos o «conjuntos sociales antropológicos» (Lischetti 2007) de la República Argentina, nos ayudaría a observar la incidencia con que la comunicación pública de ciertos fenómenos, procesos y realidades, influyó en la interpretación y la aproximación que éstos tuvieron en la sociedad en general. Asimismo, resaltamos la importancia de la comunicación de masas en la construcción tanto del presente, como del pasado y el futuro de una sociedad concreta.

A través del presente trabajo nos proponemos: a) identificar y cuantificar los artículos periodísticos referidos a pueblos originarios durante la primera década del siglo XX publicados en el Diario Los Andes de Mendoza; b) localizar las regiones geográficas a que hacen referencia los artículos; $c$ ) distinguir las formas de construcción conceptual sobre los «conjuntos sociales antropológicos» del actual territorio argentino en las noticias que difundió dicho diario durante la primera década del siglo XX en Mendoza; y d) analizar intra e intertextualmente cómo estos documentos periodísticos construyeron categorías relacionales entre el contexto histórico «nacional» y el «otro cultural».

Según el proceso de investigación en el que se encuentra el trabajo realizado, podemos permitirnos realizar una serie de proposiciones tentativas que presuponen, en primer lugar, que el Diario Los Andes construyó conceptos que forjaron un sentido común hegemónico respecto a los pueblos originarios, organizado públicamente para apreh1 enderse por la generalidad de los lectores; y, en segundo lugar, que dichas publicaciones constituyeron una herramienta legitimadora y promotora del exterminio de los pueblos originarios para la consolidación del modelo agroexportador y el papel de periferia jugado por la Argentina en la división internacional del trabajo.

\section{Materiales y método}

Para poder desarrollar los objetivos propuestos se ha procurado recopilar los artículos referidos a pueblos originarios de la Argentina publicados en el Diario Los Andes de la Ciudad de Mendoza, consultado en el Archivo de Hemeroteca de la Biblioteca Pública General San Martín de dicha ciudad. Se fotografió cada artículo identificado, tomando como datos el nombre del diario, la fecha y la página de la noticia en una ficha guía. Luego se organizaron y almacenaron en un catálogo fotográfico, dividiendo las noticias por año y, por último, se volcaron los datos principales (nombre del diario, día, mes y año del artículo, región geográfica a la que hace referencia, título y página) en una planilla de cálculo para poder cuantificar las referencias más demostrativas de las noticias. Al mismo tiempo se desglosó el contenido de los artículos periodísticos en fichas particulares de recuperación de la información que incluyeron, además de los datos tomados para la base de datos, una relación y resumen del contenido del 
artículo y de la posición inter e intratextual que los mismos ocuparon en el papel. También se tuvo en cuenta la sección del diario en la que se publicaron los mismos (López 2013).

\section{3. «Los hombres se parecen más a su época que a su padre»}

Partimos de la propuesta de Angenot, afirmando que «...una idea siempre es histórica. No se puede tener cualquier idea, creencia u opinión, mantener cualquier programa de verdad en cualquier época y en cualquier cultura» (Angenot 2010: 16).

Puede hacerse un análisis relacional entre lo que se estaba publicando en los diarios y lo que ocurría a la vez fuera de ellos estrictamente hablando. Si bien a principios del siglo XX los diarios no alcanzaban el nivel de difusión que poseen hoy en día, sí fueron parte de un proceso técnico que les dio origen y que permitió la difusión a una gran cantidad de personas, impulsado por las innovaciones ampliamente extendidas a nivel mundial desde la segunda mitad del siglo XIX por el influjo de la segunda oleada de la Revolución Industrial. Uno de los procesos más significativos que pueden observarse, desde mediados del siglo XIX y principios del XX, fue el de consolidación del Estado Nacional en varios países latinoamericanos. En dicho proceso, un lugar importante lo ocupó el engrandecimiento de la sociedad civil y la proliferación de ciertas instituciones características de ésta, como las organizaciones sindicales, la prensa y los espacios recreativos. Al mismo tiempo jugaron un papel privilegiado las instituciones de enseñanza pública creadas desde la sanción de la ley 1420 de 1884 durante la primera presidencia de Roca (1880-1886).

Con este tipo de instituciones se pudo lograr una homogeneización política y cultural que contribuyó a la consolidación del Estado Nacional Argentino. En este trabajo se considera tal consolidación teniendo en cuenta que la nacionalidad en los nuevos Estados es un producto estratégico de la expansión y consolidación de éstos $\mathrm{y}$, a la vez, afirmando que la institución central del Estado no es el gobierno sino la propiedad como factor que niega lo social, es decir, la apropiación y exclusión de los medios naturales y sociales por parte de un segmento de la sociedad (Lull 2007).

Una perfecta aclaración de la cuestión indígena abordada desde el Estado Nacional en relación con la temática planteada, la constituye el proyecto del médico y abogado de origen español Juan Bialet Massé. El gobierno del Estado Nacional, presidido por Julio Argentino Roca en su segunda presidencia (1898-1904), le encomendó una descripción integral de las masas trabajadoras del «interior» del país. Bialet Massé recorrió muchas regiones de nuestro país, principalmente el Chaco, y redactó el famoso «Informe sobre el estado de las clases obreras argentinas», calificando a los «indios» como incapaces, analfabetos, incomunicados y dudando de sus cualidades «racionales». En este informe, propuso la formación de reducciones o colonias para «integrar a los pueblos originarios a la vida civilizada», y recomendó la creación de un Patronato Nacional de Indios (Martínez Sarasola 2005: 349; el subrayado es nuestro).

Si bien este proyecto no fue aplicado en forma fáctica, muchos de sus conceptos continuaron existiendo en la vida política y militar del país, y contribuyó al desarrollo de políticas estatales posteriores en relación con los pueblos originarios preexistentes 
a la formación del Estado Nacional. Por un decreto del 24 de julio de 1912 se estableció que el trato con los «indios» quedaría a cargo de la Dirección de Territorios Nacionales, cuyas premisas fundamentales eran la reducción, la protección y la instrucción:

«Reducción, protección e instrucción es la trilogía eufemística sobre la cual parece asentarse el marco ideológico de las políticas imperantes en la época. Reducción significaba en la práctica confinamiento, separación, segregación. Protección implicaba que los indígenas no estaban en condiciones de actuar por sí mismos. Instrucción era aislarlos, desgajarlos de las pautas culturales ancestrales» (Martínez Sarasola 2005: 353).

Durante el gobierno del presidente Victorino de la Plaza (1914-1916), se creó en 1916 la Comisión Honoraria de Reducciones de Indios, fundamentada en la «necesidad de centralizar en un solo organismo todos los asuntos relacionados con la reducción, y civilización de los indígenas» (Martínez Sarasola 2005: 357). Dicha comisión estaba imbuida de valores negativos que alentaron la construcción del «sentido común» social: la calificación de «vagos» atribuida a los indígenas. Estas acepciones legitimaron el sometimiento de los pueblos originarios, acelerando el proceso de subsunción del trabajo al capital (Gordillo 1992), entre otras cuestiones.

\section{4. «Dime de qué hablas y te diré qué eres»}

Por medios de comunicación masiva entendemos a aquellos organismos que tienen el monopolio en la difusión de la información en un contexto social amplio, es decir, en vez de comunicar, in-forman (dan forma a un discurso para que sea apropiado por la sociedad). No pueden dejarse de lado ni la trayectoria histórica en la que se inscribe ese «monopolio» ni los «intereses» existentes. Es necesario conceptuar a dichos medios como unidades de apropiación, selección y distribución de experiencias en una sociedad. Estas tres características hacen referencia a que estos organismos, como espacios autorizados, toman legítimamente recortes de la realidad para elaborar un discurso que será in-formado al público general, es decir, se dará forma al «sentido común» para ser apropiado para la sociedad (López 2013, Sironi 2011).

Dicha caracterización está ampliamente relacionada con el concepto gramsciano de «hegemonía», que establece que el dominio de las clases dominantes no es sólo en virtud de su aparato represivo sino, y ante todo, porque una mayoría de la población continúa viviendo según el sistema de vida que las clases dirigentes han construido. A esto hace referencia Gramsci cuando habla del «consentimiento espontáneo de las grandes masas de la población a la dirección impresa a la vida social por el grupo fundamental dominante, consentimiento que proviene históricamente del prestigio (y por tanto de la confianza) que dan al grupo dominante su posición y su función en el mundo de la producción» (Gramsci 1967: 34); siempre teniendo en cuenta «las fuerzas que históricamente obran en las sociedades, y en el mundo en general, son más poderosas que los media o que la influencia inmediata que puedan ejercer» (McQuail 1991: 29). De esta forma, incluimos a dichos organismos en la conceptuación planteada por Louis Althusser (1968) en referencia a los Aparatos Ideológicos del Estado (AIE); es decir, que la influencia que los medios de comunicación de masas tuvieron 
(y tienen aun más hoy en día) como «constructores de hegemonía» es una variable esencial a la hora de analizar las construcciones discursivas de medios hegemónicos sobre sectores subalternos, ya que son canales a través de los cuales se imprime dirección e ímpetu a los cambios sociales.

Este trabajo también está enmarcado en algunos aportes del Análisis Crítico del Discurso, que se refieren a que «la perspectiva del ACD requiere una aproximación 'funcional' que vaya más allá de los límites de la frase, y más allá de la acción y de la interacción, y que intente explicar el uso del lenguaje y del discurso también en los términos más extensos de estructuras, procesos y constreñimientos sociales, políticos, culturales e históricos» (Van Dijk 1999: 25).

El Diario Los Andes fue fundado en la Ciudad de Mendoza el 20 de octubre de 1882 por el Dr. Adolfo Calle, para promover la candidatura de Rodolfo Zapata a diputado nacional. En sus comienzos «el diario aparecía los martes, jueves y sábados por la tarde, pero desde 1885 se convirtió en una publicación diaria y matutina» (Bustelo y Rossignoli 2004: 447-448). En un primer momento, aunque naciendo con un perfil militante, el diario quiso mostrar su carácter independiente respeto a las políticas nacionales del presidente Roca. Sin embargo, durante la presidencia de Juárez Celman, desde 1886 adoptó posiciones francamente favorables al mismo. Durante la primera década del siglo XX, en sus páginas aparecieron críticas despiadadas hacia Emilio Civit, aliado de Roca y gobernador de la provincia de Mendoza en dos oportunidades (1898-1901 y 1907-1910), sin duda la principal figura política de la oligarquía mendocina a comienzos de siglo. Ya se ha caracterizado a los diarios en Mendoza desde fines del siglo XIX como los difusores de los proyectos de la élite dirigente.

\section{5. «Dime de qué hablas y te diré quién eres»}

Se recuperaron un total de 187 noticias relacionadas con los pueblos originarios de la Argentina, entre 1900 y 1909. En la generalidad de los artículos periodísticos analizados puede notarse el uso del término «indio» para referirse a los pueblos originarios $\mathrm{y}$ en muchos otros se habla de «desierto», concepto difuso, usado para referirse a las posesiones y prácticas de las culturas autóctonas, obervando que «el significado habitual del término desierto referido a un espacio vacio, en una operación no explícita, se hace extensible a vacío de civilización» (Lois 2001: 101). Partimos de la postura de Bonfil Batalla, insistiendo en que la categoría de «indio» es una categoría supraétnica que no denota ningún contenido específico de los grupos que abarca, sino una particular relación entre ellos y otros sectores del sistema social global del que los indios forman parte. La categoría de indio denota la condición de colonizado y hace referencia necesaria a la condición colonial (Bonfil Batalla 1992), oculta y niega las identidades de los distintos grupos étnicos que habitaban y habitan América, devuelve la imagen de un observador que crea el estereotipo conforme a sus intereses de dominación (Fraguas y Monsalve 2007). No es la intención de este trabajo representar la voz de los silenciados, sino entender y nombrar los lugares donde sus demandas o su vida cotidiana entran en conflicto con los otros (García Canclini 2004). 
En los artículos periodísticos consultados se habla de los conjuntos sociales antropológicos como sujetos próximos a entrar en las sendas del progreso y la civilización, abordados como entes pasivos que entran en acción y progreso al estar en contacto con otros ajenos a su pueblo, como son los funcionarios del Estado Nacional en muchos casos. Hay muchas calificaciones peyorativas hacia los pueblos originarios. Así, un artículo del Diario Los Andes dice que «A pesar de que la vida de los indios es miserable, alcanzan una edad desconocida en nuestros países civilizados. Es frecuente hallar ejemplares de más de 100 años» (Diario Los Andes 04/11/1903: 5). Esta cita es un ejemplo de la referencia hacia los pueblos originarios desde un medio de prensa escrito, en el que se inscriben una larga serie de notas con el mismo carácter, donde se exageran ciertos rasgos para causar repulsión, se tergiversan factores biológicos como la edad y se cosifica a los indígenas (por ejemplo cuando se habla de «ejemplares»). Estas, como otras muchas descripciones, tenían como uno de sus objetivos la negación de las posesiones territoriales de las culturas autóctonas. Ello se proponía en pos de la necesidad y de la disponibilidad del suelo para fines puramente productivos, y además buscaba lograr la hegemonización política-cultural sobre una base identitaria proyectada desde el presente (Carrizo 2010). En un artículo referido a expedicionarios enviados por el gobierno nacional a los territorios del Chaco se dice que

«El señor Villamayor viene profundamente impresionado por el estado de miseria y de abandono en que viven los indios de aquellos parajes, muertos de hambre y careciendo de todo. Si alguna vez tienen contacto con los civilizados que viven en los lugares poblados más cercanos de las tolderías es para ser inicuamente explotados en los ingenios o atacados por los destacamentos militares de guarnición en los diversos fortines.

Los naturales se apartan cada vez más de las poblaciones y llevan un justo rencor contra los hombres civilizados que así los maltratan.

El jefe de la expedición cree llegado el momento de que el gobierno y el pueblo en general se ocupen de esos infelices que podrían ser elementos muy útiles al país si se les ayudase un poco y se hiciera algo por inculcarles siquiera rudimentos de nuestra civilización» (Diario Los Andes 11/01/1907: 5).

Esto se enmarca en el proceso de consolidación del Estado Nacional desde la segunda mitad del siglo XIX, acentuado desde 1879. Siguiendo a Gnecco (2004) y a Carrizo (2010) es importante señalar que durante la conformación de los nuevos estados de América Latina del Siglo XIX, las sociedades pasaron de ser dominadas por el poder español, a ser dominadores de los grupos culturales subalternos y de sus territorios respectivos, y en ello el Estado tuvo mucha participación (Carrizo 2010). Esto explica que el paradigma de conquista y dominación continuó existiendo, esta vez desde un Estado cada vez más consolidado hacia poblaciones (y tierras) de culturas autóctonas preexistentes a éste; con su correlato de ocupación y usurpación de territorios habitados y producidos por estas culturas. Es necesario aclarar que «si bien la mayor parte de los discursos coincidían en la necesidad de incorporar y homogeneizar a los indígenas en la matriz estado-nación-territorio, éstos continuaron siendo otro lo suficientemente visible como para no ser colocado dentro del conjunto de los ciudadanos argentinos» (Delrio 2002: 236). 
Gran parte de las noticias hacen referencia a territorios nacionales tratados de conquistar y apropiar por el Estado Nacional en la Patagonia y el Chaco (como región que abarcaba en términos aproximativos las actuales provincias de Chaco, Formosa, Norte de Santa Fe, Norte de Santiago del Estero, Tucumán). En relación con la primera, es necesario destacar la existencia de artículos referidos a exploraciones en territorios nacionales, como Santa Cruz, con una intención de promocionar tierras deshabitadas por ciudadanos del Estado, para que sean ocupadas por éstos y con la intención de dar ciertos visos de estabilidad y legitimidad a las tierras que iban siendo incorporadas al Estado Nacional y hurtadas a las poblaciones originarias. También se proponía en los artículos periodísticos la organización de empresas de colonización, como lo declara un artículo refiriéndose a la zona de Chubut al comunicar que «El gobierno ha recibido una nota de las autoridades del Chubut en la que estas le aconsejan la fundación de colonias agrícolas en ese territorio utilizando a los mismos indígenas» (Diario Los Andes 08/08/1907: 4).

Respecto al Chaco, muchos documentos periodísticos proponen la formación de colonias militarizadas, es decir: misiones, para que los indios entren en las vías del «progreso y la civilización», conformadas por extranjeros e indígenas subyugados. Este rasgo particular está vinculado con la necesidad de incorporar mano de obra barata a los obrajes que, para esta época, constituían la principal actividad productiva, implicando «...la consolidación de un nuevo modelo de país basado en la agroexportación y en la política inmigratoria para proveer de mano de obra al 'granero del mundo'» (Palermo 2000: 380), que trajo la conquista del último baluarte indígena: los montes del Chaco. Así, se dice en una noticia que «El indio muestra condiciones especiales para el trabajo de zafra y es al mismo tiempo un jornalero de poco costo. Se les hace trabajar de las 6 a.m hasta las 5 p.m., dándoseles dos horas de descanso. El salario es bastante modesto é importa un desembolso mensual de 18 á 20 pesos por cada trabajador» (Diario Los Andes 06/07/1900: 4).

Junto a las notas que manifestaban la necesidad de formar colonias y reducciones para someter a los indígenas a la «vida civilizada» y al efectivo dominio del Estado, aparece una gran variedad de documentos periodísticos que hacen hincapié en una realidad militarizada en la región, en múltiples campañas militares y conflictos bélicos en la zona del Chaco. Es decir que muchas remitían a una situación de inestabilidad para el Estado Nacional, de desequilibrio interno. Un buen ejemplo de lo dicho es una carta que un expedicionario escribe al gobierno nacional solicitándole permiso para realizar una expedición al Chaco arguyendo que «Se me ha argumentado por algún buen amigo, que sería una temeridad lanzarme por esos desiertos condenados, que a la primera de cambio concluirían con mi vida» (Diario Los Andes 09/05/1905: 4 ), u otra explicando que «Si no fueran los cuatreros, salteadores y uno que otro mocovie que puebla en la misma provincia de Santa $\mathrm{Fe}$, y que sorprende á los pobladores con sus robos de ganado, puede afirmarse que este Chaco puede quedar limpio de salvajes tobas y matacos, para principios del año 1901» (Diario Los Andes 03/08/1900: 5). La aparición del título «Matanza de indios» en numerosos artículos del diario de la época da muestra de la situación existente, y justamente esa expresión es utilizada como una herramienta del Estado en el proceso de consecución de tierras e indígenas para incorporarlas al Estado y al sistema económico vigente, manipulando, junto a 
esto, la inestabilidad regional divulgada masivamente en beneficio de las clases dirigentes. Al mismo tiempo se da cuenta de que los «indios» del Chaco estaban obteniendo armas y municiones modernas para defenderse. Se interpreta en los artículos, además, el descontento de los indígenas por la explotación a la que los estancieros los sometían, y se dice que algunas de las reacciones violentas de estos pueblos son debidas a dichos tratos, como lo expresa la siguiente nota:

«El general Winter ha recibido los datos y documentos comprobatorios del intercambio de armas y municiones por cueros de lobos y ciervos realizado por los indígenas del Chaco con algunos habitantes de esos parajes (...) Winter en conferencia con el ministro de la Guerra, declaró que había mucha veracidad en las denuncias y que es tremenda la explotación á los indios que hacen algunos estancieros del Chaco» (Diario Los Andes 17/02/1900: 4).

Hemos podido observar en el periódico cierto descontento por la situación militar en la región y la consecuente pérdida de recursos humanos y materiales que habrían podido ser aprovechados y utilizados de otra forma por el Estado, con resultados más favorables tanto para las finanzas estatales como para las poblaciones locales, aunque en esta crítica muchas veces avalada por proyectos de construcción de misiones o reducciones, no puede dejar de verse una intención implícita: la necesidad, como se viene diciendo, de incorporar mano de obra barata a obrajes e ingenios de una forma más rápida (Martínez Sarasola 2005).

Se concuerda en que

«Pasadas dos décadas desde la campaña al desierto, sin embargo, el indio reaparece en un discurso dirigido a resaltar positivamente aspectos de su cultura, tales como el idioma. Pero este reconocimiento sólo es posible bajo una forma compatible con un paradigma asimilacionista: esto es, reconocer lo distinto como desplazado a una etapa evolutiva previa, o desviada, por fuera de la actual nación civilizada» (De Jong 2001: 196).

Muchas veces se ha visto utilizado en los artículos el calificativo de «salvajes» refiriéndose a los indígenas, lo que pareciera ser, además de lo expuesto, una interpretación dentro de un esquema evolucionista unilineal típico de fines del siglo XIX y principios del siglo XX. Este esquema, plasmado en los supuestos categóricos de Salvajismo-Barbarie-Civilización delineados por Morgan (1986) y, con diferente acento, por Spencer (1873) y Tylor (1995), legitimó el establishment impuesto y promovido por las clases dirigentes argentinas. Estas trataron de emular acríticamente los esquemas sociales y culturales de las fracciones sociales privilegiadas de los principales países industriales europeos de la época (Francia e Inglaterra) ${ }^{1}$.

1 Cabe destacar que dichos supuestos se insertan en lo que se denomina el Modelo Antropológico Clásico (Menéndez 1967-68). Esto es, el conjunto de tendencias teóricas -evolucionismo, difusionismo, funcionalismo, etc.- que comparten «la unidad de análisis» (la comunidad nativa) y un contexto colonial propio del origen y desarrollo del objeto de la antropología. Este modelo re-presenta -hace presente- el corpus de datos y teorías que fue acumulando desde las distintas perspectivas, incorporando «a la cotidianeidad de los actores de la sociedad en su conjunto, como el resumen de contenido de las ideas acerca de los 'conjuntos sociales antropológicos'» (Lischetti 2007: 32), y desarrollando una imagen estática y ahistórica de los sistema socioculturales estudiados. Dicha ahistoricidad, genera efectos sobre los grupos en estudio, estimulando las desigualdades entre Occidente y el resto del mundo, perpetuando las características etnocéntricas marcadas por 
Un artículo relativo a una de las tantas expediciones militares enviadas por el gobierno nacional al Chaco refiere que

«Este hecho para nuestro país, representa en su sencillez, el esfuerzo y el poder de la nación, que circunscribiendo la acción del salvaje a un radio, donde imposibilita sus depreciaciones, vá obligando paulatinamente y sin llegar a la represión sanguinaria ó al exterminio, á que esa única parte del país que aún queda libremente habitada por las tribus tobas y otras, comprendan su impotencia y acudan a someterse a las fuerzas nacionales, incorporándose así al movimiento de progreso que se nota en estos hechos materiales que presagian el futuro de civilización que también alcanzará a esa frondosa región» (Diario Los Andes 14/02/1903: 5).

Existen también referencias directas a campañas militares: «El general Winter partirá á principios de marzo a Resistencia llevando los elementos necesarios para reanudar las operaciones contra los indios, y establecer una línea en los fortines que salve a las regiones pobladas de los ataques de los salvajes» (Diario Los Andes 11/02/1900: 4).

En numerosos artículos (aunque en una cantidad mucho menor que las referidas a los pueblos originarios en una situación bélica) se destaca la violencia de las campañas realizadas por el Estado y la devastación que producían las tropas militares en las regiones que ocupaban para someter a los pueblos originarios, aunque siempre desde una perspectiva asimilacionista, argumentando que si el trato hacia dichos pueblos fuera diferente, sería más sencillo incorporarlos a las sendas de la civilización, como lo destaca el siguiente documento histórico-periodístico: «A pesar de las sociedades formadas en estos últimos tiempos con altruistas fines de proteger a las razas indígenas dominadoras en otros tiempos, hay un ensañamiento en perseguir a los pobres indios por parte de ciertas autoridades de los territorios nacionales que causa verdadera indignación» (Diario Los Andes 19/12/1906: 5).

Es necesario destacar que en muchas de los artículos periodísticos analizados se hace referencia a los hombres (tanto militares como civiles) que participaron en las campañas de exploración (y expropiación) en las regiones densamente pobladas por pueblos originarios del Chaco y la Patagonia; se los describe y difunde como héroes, como arquetipo de «argentinos», baluartes de la civilización, con un cariz paternalista hacia los «indios» (Blengino 2005). A dichos hombres se les adscriben virtudes morales entre otras cosas para generar consenso en relación con el proceso de ocupación del Chaco continuado durante el siglo XX. Un ejemplo refiere que

«Hay en nuestro país algunos hombres abnegados que periódicamente realizan excursiones atrevidas hacia las entrañas del Chaco donde van, sin medir peligros ni calcular sinsabores, a compartir con el indio, soberano de esas regiones, las horas silenciosas de los bosques profundos que han crecido con exuberancia salvaje en aquella región amplísima y fértil de nuestro país, cuyas tierras libérrimas esperan las rejas de los arados para producir riquezas, lo mismo que las selvas impenetrables aguardan el hacha

\footnotetext{
la situación y dominación colonial. En palabras de Menéndez (2010), las definiciones del objeto de estudio inicial (el «primitivo») de la disciplina antropológica «expresan no solo intereses académicos, sino concepciones ideológicos respecto de un sujeto de estudio, cuyas características posibilitan y justifican tanto la prioridad de la cultura occidental, como la Fundamentación de su expansión y dominación a través de presupuestos ideológicos utilizados como si fueran criterios científicos» (Menéndez 2010: 37).
} 
del desmonte para rendir sus tallos sobre las cortantes sierras de los obrajes» (Diario Los Andes 25/01/1907: 5).

Junto a los elogios a esos hombres, también reconocen méritos del Gobierno Nacional, representado por el ejército nacional diciendo, por ejemplo, que «la conquista del Chaco avanza, sin embargo, y parte de su vasto territorio está incorporado hoy, de una manera definitiva, a la vida civilizada, gracias al esfuerzo de algunos hombres activos y emprendedores, y un poco también, á la acción, sino persuasiva, contundente, del ejército nacional» (Diario Los Andes 06/07/1900: 4).

Un tema que merece cierta atención es una serie de artículos que destacan la «exposición de indios» en Europa y Estados Unidos. Esto quiere decir que expedicionarios o exploradores sustraían pobladores originarios de sus tierras y los trasladaban a reuniones científicas o museos en Europa o Estados Unidos, donde eran observados, estudiados, medidos, interpretados, etc. A la vez, tiene relación con esta línea antropológica positivista-evolucionista de la que veníamos hablando. Uno de los documentos periodísticos, hablando de unos «indios» araucanos traídos de Chile y estacionados en Buenos Aires por un tiempo con destino próximo a París, dice lo siguiente:

«Cuando hace algunos meses una compañía artística intentó aquí llevar varios indios del Chaco para exhibirlos en un circo de París, la opinión pública se sublevó contra esa pretensión inhumana cuyo objeto era exponer ante el extranjero en la capital más culta de Europa, lo que queda de salvajismo de América, lucrando con la barbarie de unos cuantos infelices arrancados de las selvas [...] Los europeos pensarán, y con razón, que la América no tiene otra cosa que exponer que los restos de su barbarie, porque parece que tenemos á gala decir á todo el mundo que todavía no hemos sido capaces de civilizar las tribus que quedan libres en sus montes, mientras en todos los tonos cantamos nuestros progresos y nuestras maravillas de órden social» (Diario Los Andes 02/05/1900: 4).

Ha podido observarse que en muchos casos la palabra «indio» es utilizada como un recurso discursivo para los debates y los conflictos políticos, el indio como metáfora de corrupción, atraso, violencia, incapacidad, deficiencia. Así, el Diario Los Andes, en su lucha política desplegada contra los Civit en Mendoza, utiliza en innumerables oportunidades la palabra «indio» para referirse despectiva y agresivamente hacia estos, en una lucha interoligárquica. La expresión «Los indios en el gobierno», «Peleas como indios» $\mathrm{o}$ «Los caciques provinciales» son algunos de los términos recurrentes en esa lucha política de principios del siglo XX. No es extraña a la vida cotidiana de la generalidad de las personas la utilización del término «indio» para referirse a algo «anormal» y fuera del patrón aceptado de comportamiento.

\section{6. «Dime de qué hablas y te diré quién fuiste»}

Un punto para destacar en nuestro análisis es la aparición de artículos, 16 en total (uno en 1902, once en el año 1906 y cuatro en 1908) que, referidos a una serie de sucesos que han sido denominados en el diario como «Episodios históricos», destacaban los principales hechos que sucedieron en el pasado en relación con el día de publicación del diario. Lo relevante es que varias fechas consideradas «históricas» son relativas a 
Figura 1: Reacomodamiento del mapa indigena: el confinamiento de fines del siglo XIX. Tomado de Martinez Sarasola (2005: 303).

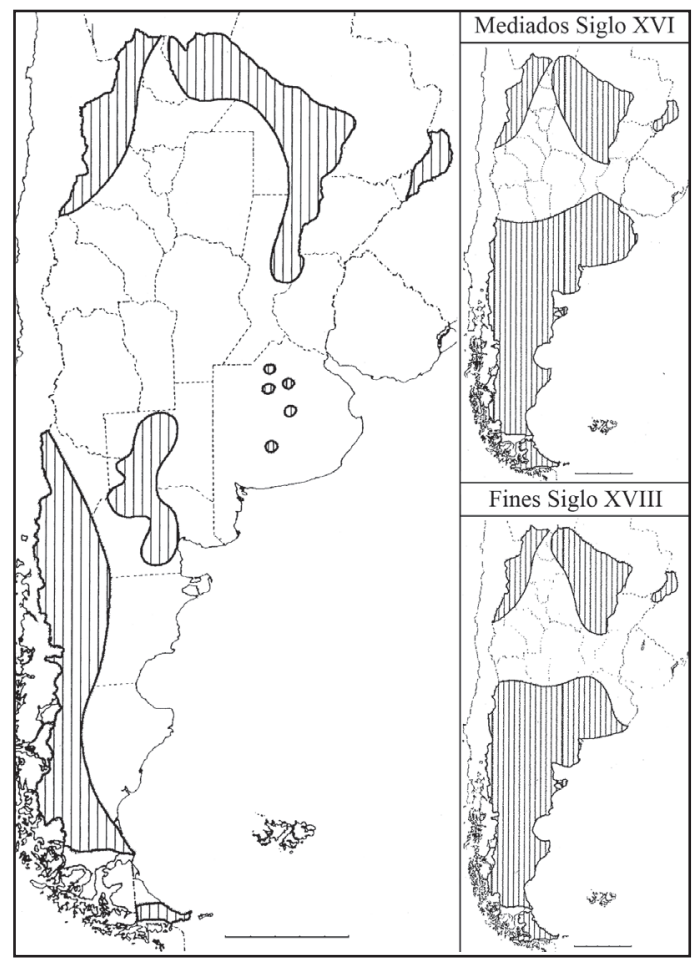

conflictos bélicos con los pueblos originarios y que han sido incorporados a una historia del país como hechos claves en la formación de la Argentina moderna. Hay gran variedad y heterogeneidad de fechas y sucesos, de toda índole, aunque se privilegian las cuestiones políticas y militares particulares (en nuestro caso las notas se refirieron en su totalidad a conflictos bélicos). Pueden encontrarse en una misma columna de dicho apartado fechas históricas como la del asesinato de Ángel Peñaloza ${ }^{2}$ en 1863 y una expedición hacia tierras patagónicas, por ejemplo. Por lo tanto, se incorporó a los pueblos originarios como parte de un pasado (remoto o reciente) que colaboró en la construcción de una nacionalidad proyectada siempre desde el presente, y en beneficio de las clases dirigentes argentinas (Figura 1).

En un artículo correspondiente al 11 de diciembre de 1902, se habla sobre ciertos estudios poblacionales en la Argentina publicados en el $9^{\circ}$ Boletín Demográfico Argentino. Según dichos estudios, la población probable en la Argentina para el 31 de diciembre de 1901 sumaba un número de 4.926.913 habitantes. Lo relevante de la nota periodística en el trabajo que nos compete es que da cuenta del número de habitantes «indios» como un total exacto (30.000 en todo el país), cuando es una cifra que en términos estrictos era imposible obtener en momentos de crisis bélica y de zonas aún no absorbidas por el Estado Nacional. La misma nota destaca que en el censo

2 Caudillo riojano opositor al gobierno nacional y a las políticas de «guerra de policía» y Unidad a Palos durante la presidencia de Bartolomé Mitre. 
de 1895 no se tuvo en cuenta en el número total de pobladores a las comunidades de pueblos originarios. Sumando las cifras de estas comunidades y de los argentinos residentes en el extranjero (ambas no cuantificadas por el censo del 95), la población total de la República Argentina en los comienzos de 1902 era, según dicho boletín, de 5.026.913 habitantes. Es interesante este apartado ya que muestra hasta qué punto las comunidades de pueblos originarios no eran tenidas en cuenta por los planes del gobierno nacional, y sí aparecían en escena en cuestiones bélicas, o cuando las empresas necesitaban mano de obra barata o tierras.

\section{Discusiones finales}

A través de la cuantificación y localización geográfica de las noticias (Figura 2), se observa un claro predominio de artículos referidos a la región del Chaco. De los 187 documentos periodísticos recuperados, 121 pertenecen a dicha zona. Cantidades mucho menores de notas proceden de otras zonas, como Patagonia, con 19 artículos periodísticos. Estas dos primeras zonas fueron tomadas como regiones que actualmente están compuestas por varias provincias. Las demás regiones a las que hacen referencia los artículos restantes fueron tomadas por los territorios provinciales propiamente dichos (Santa Fe, Córdoba, Mendoza, Santiago del Estero, La Pampa, Salta y Jujuy). En relación con Buenos Aires, las noticias pueden dividirse en dos secciones: a) las que se refieren a territorios del sur de dicha provincia - en relación estricta con las situaciones en Patagonia- y b) las que denotan el carácter de cabeza política, administrativa y científica de la Capital Federal en la que se realizan eventos, se dictan políticas de Estado y se estacionan transitoriamente personas para ser trasladadas a otras regiones del mundo.

La mayor cantidad de noticias recuperadas son del año 1900 (44 artículos), luego descienden en cantidad, pero se equilibran durante toda la década, quizás muestra de la continuidad «normal» de la crisis bélica en los territorios nacionales. A la vez, la gran cantidad de noticias sobre el tema del «indio» en su generalidad da cuenta de la relevancia política, económica y social de la temática en la época abordada.

Nuestro análisis discursivo, y la cuantificación realizada, permite observar la importancia estratégica de la «cuestión chaqueña» en la política del gobierno nacional durante la primera década del siglo XX. En los diarios de la época este tema se plantea con mucho énfasis y son abordadas variables de todo tipo (desde temas bélicos, pasando por observaciones etnográficas, hasta formación de colonias e industrias, entre otros). Al mismo tiempo, la región de Patagonia ocupó un lugar importante (cuantitativamente) en las noticias, aunque menos que la primera región. Muchos artículos hacen referencia a venta de tierras «fiscales», que han sido apropiadas y cuya venta se ha intentado incluso antes de que el gobierno nacional consiga expropiárselas a los pueblos originarios.

Los términos en los que son planteadas las cuestiones indígenas podrían hacernos reflexionar sobre la influencia que la comunicación de masas tuvo y tiene en la sociedad en general. Esta influencia se materializó en la imposición de ciertas categorías 
Figura 2: Cantidad de noticias según año y región.

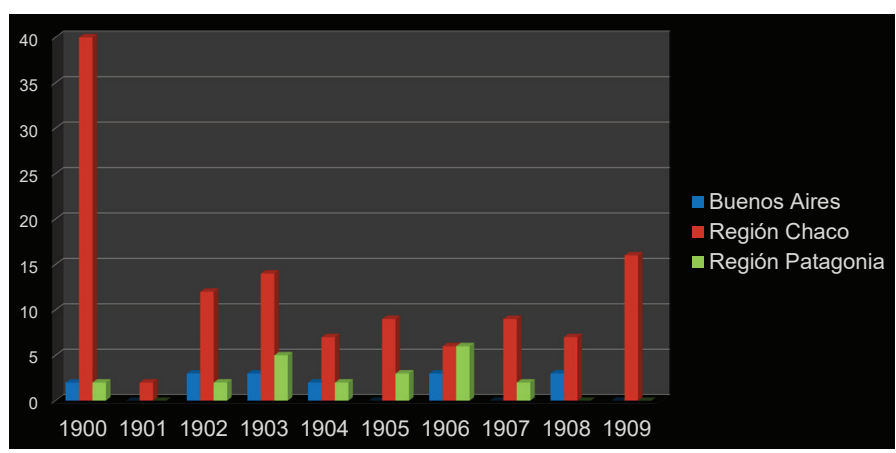

de construcción social, que perduran hasta el día de hoy cuando nos referimos a cualquier rasgo de los pueblos originarios.

Queda demostrado, en la gran cantidad de artículos analizados, cierto tratamiento y construcción discursiva que asoció al «indio» con el delincuente y, por extensión, con la marginalidad. Categorías como salvajismo, atraso, violencia, barbarie, pasividad, se atribuyeron con fuerza a los pueblos originarios, delimitando así, la construcción de un discurso plural para la consolidación del proyecto hegemónico del Estado Nacional, sustentado en la expansión del modelo agroexportador y la consiguiente expansión de la frontera agrícola. Este tuvo como uno de sus objetivos la imposición y constitución descalificadora del «otro cultural»y la constante recurrencia a la asimilación en un patrón único de ser nacional.

Si bien nuestro trabajo aborda la problemática de los grupos originarios como otro cultural construido en los artículos periodísticos, estos no son concebidos de forma aislada del conjunto de la sociedad, sino pensados como parte de los sectores subalternos y desposeídos (proletarios, indios, enfermos, entre otros). La violencia desnuda, directa, es fundadora de las relaciones sociales y, así, emerge en el momento de fundación o refundación de dichas relaciones. Éstas van conformando un entramado, construyendo una territorialidad. Se había desarrollado, en efecto, una nueva territorialidad, un territorio que pugnaba con otro territorio, ambos asentados sobre una misma geografía.

La evidencia discursiva estudiada en este trabajo ha permitido observar cómo se construyó un discurso difundido socialmente que legitimó el accionar del Estado Nacional (y los propietarios en general) hacia las comunidades originarias del actual territorio argentino. Estos discursos, apropiados masivamente, fueron asumidos por el conjunto social como lo «natural», lo «real», lo «normal».

En estos tiempos, en los que la sociedad argentina ha conquistado la Ley de Servicios de Comunicación Audiovisual (sancionada en el año 2009), el papel de los medios de comunicación como formadores de opinión y constructores de otredad ha sido cuestionado y desenmascarado. Consideramos que como comunidad científica, debemos capitalizar esto y generar espacios de pensamiento crítico hacia dentro y fuera de estos medios, dándole contenido al espíritu plural de dicha ley.

Creemos que es nuestra tarea, desnaturalizar, indagar y cuestionar construcciones conceptuales que perjudican a los sectores sociales subalternos en beneficio de intereses económicos y políticos. 


\section{Referencias bibliográficas}

AlthUSSER, Louis

1968 La filosofía como arma de la revolución. México: Siglo XXI.

Angenot, Marc

2010 El discurso social. Buenos Aires: Siglo XXI.

BLENGINO, Vanni

2005 La zanja de Patagonia. Los nuevos conquistadores: militares, cientificos, sacerdotes y escritores. Buenos Aires: Fondo de Cultura Económica.

Bonfil Batalla, Guillermo

1992 Identidad y pluralismo cultural en América Latina. Buenos Aires: CEHASS.

Bustelo, Gastón y Alejandra Rossignoli

2004 «Los medios de comunicación: de la primera imprenta a los multimedios», en Mendoza. Cultura y economía, Arturo Roig, Pablo Lacaste y María Cristina Satlari, comp., pp. 435-472. Buenos Aires: Caviar Bleu Editora Andina Sur.

CARrizo, Sergio

2010 «Exploraciones arqueológicas en la construcción del territorio tucumano a fines del siglo XIX y principios del siglo XX», en Historias de arqueología sudamericana, Javier Nastri y Lucio Menezes Ferreira, eds., pp. 55-76. Buenos Aires: Fundación de Historia Natural Félix de Azara.

De Jong, Ingrid

2002 «Indio, nación y soberanía en la cordillera norpatagónica: fronteras de la inclusión y la exclusión en el discurso de Manuel José Olascoaga», en Funcionarios, diplomáticos, guerreros. Miradas hacia el otro en las fronteras de Pampa y Patagonia (siglos XVIII-XIX), Lidia R. Nacuzzi, comp., pp. 159-202. Buenos Aires: Sociedad Argentina de Antropología.

DELRIO, Walter

2002 «Indios amigos, salvajes o argentinos. Procesos de construcción de categorías sociales en la incorporación de los pueblos originarios al estado-nación», en Funcionarios, diplomáticos, guerreros. Miradas hacia el otro en las fronteras de Pampa y Patagonia (siglos XVIII-XIX), Lidia R. Nacuzzi, comp., pp. 203-246. Buenos Aires: Sociedad Argentina de Antropología.

DIARIO LOS ANDES

1900-09Archivo de Hemeroteca Biblioteca Pública General San Martín, Ciudad de Mendoza.

Fraguas, Noemí y Patricia Monsalve

2007 «Procesos de conformación de la identidad étnica en América Latina», en Antropología, Mirta Lischetti, comp., pp. 181-206. Buenos Aires: EUDEBA.

García CANClini, Néstor

2004 Diferentes, desiguales y desconectados. Barcelona: Gedisa.

GLADE, William

1991 «América Latina y la economía internacional, 1870-1914», en Historia de América Latina, Tomo VII: América Latina: economía y sociedad, c. 1870-1930, Leslie Bethell, ed., pp. 1-49. Barcelona: Crítica. 
GNECCO, Cristóbal

2004 «La indigenización de las arqueologías nacionales» en Teoría Arqueológica en América del Sur, Gustavo G. Politis y Roberto D. Peretti, eds., pp. 115-129. Buenos Aires: INCUAPA.

GordiLlo, Gastón

1992 «Procesos de subsunción del trabajo al capital en el capitalismo periférico», en $\mathrm{An}$ tropología económica II: Conceptos fundamentales, Héctor H. Trinchero, comp., pp. 45-67. Buenos Aires: CEAL.

GramsCI, Antonio

1967 Cultura y literatura. Madrid: Ediciones Península.

LischetTI, Mirta

2007 «La antropología como disciplina científica», en Antropología, Mirta Lischetti, comp., pp. 9-84. Buenos Aires: EUDEBA.

LoIs, Carla

2001 «Desierto y territorio: imágenes decimonónicas del Gran Chaco argentino», Mundo de Antes. Revista del Instituto de Arqueología y Museo 2: 97-116. Tucumán.

LóPEz, Manuel

2013 Análisis sobre la divulgación periodística de la arqueología en Mendoza entre 1900 y 1939: el caso del Diario Los Andes. Mendoza: Universidad Nacional de Cuyo.

LuLl, Vicente

2007 Los objetos distinguidos. La arqueología como excusa. Barcelona: Ediciones Bellaterra.

Martínez Sarasola, Carlos

2005 Nuestros paisanos los indios, $8^{\text {a }}$ ed. Buenos Aires: Emecé.

McQuAIL, Denis

1991 Introducción a la teoría de la comunicación de masas. Barcelona: Paidós.

MENÉndez, Eduardo

1967-68El modelo antropológico clásico. Buenos Aires. Ms.

2010 La parte negada de la cultura. Relativismo, diferencias y racismo. Rosario: Prohistoria ediciones.

Morgan, Lewis

1986 La sociedad primitiva [1877]. México: Editorial Quinto Sol.

Palermo, Miguel Ángel

2000 «A través de la frontera. Economía y sociedad indígenas desde el tiempo colonial hasta el siglo XIX», en Nueva historia argentina, Tomo I: Los Pueblos Originarios y la Conquista, Myriam Noemi Tarragó, dir., pp. 343-382. Buenos Aires: Sudamericana.

Sironi, Osvaldo

2011 «La felicidad es un arma ardiente: un acercamiento antropológico a los films Elephant y Bowling for Columbine», en Contribuciones a las Ciencias Sociales 15 (noviembre, 2011). Málaga: Grupo EUMED.net. Documento electrónico, http:// www.eumed.net/rev/cccss/15/ohs.html, con acceso el 14 de diciembre de 2013. 
SPENCER, Herbert

1873 The Study of Sociology. Londres: Henry J. King y Co.

TYLOR, Edward B.

1995 «La ciencia de la cultura» [1871], en El concepto de cultura. Textos fundamentales, J. S. Khan, comp., pp. 29-46. Barcelona: Anagrama.

VAN DiJK, Teun

1999 «El análisis crítico del discurso». Anthropos 186: 23-36. Barcelona. 